\title{
Implantación de recursos didácticos digitales en asignaturas de Organización de Empresas
}

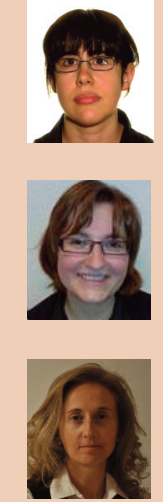

\section{Ana Núñez Carballosa}

Profesora Titular del Departament d'Economia i

Organització d'Empreses de la Universitat de Barcelona

ana.nunez@ub.edu

Mercè Bernardo Vilamitjana

Lector del Departament d'Economia i Organització

d'Empreses de la Universitat de Barcelona

merce.bernardo@ub.edu

Laura Guitart Tarrés

Profesora Titular del Departament d'Economia i

Organització d'Empreses de la Universitat de Barcelona laura.guitart@ub.edu

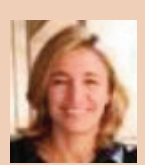

Paloma Miratvilles Matamoros

Profesora Titular del Departament d'Economia i

Organització d’Empreses de la Universitat de Barcelona

paloma.miratvilles@ub.edu

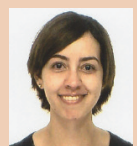

Fariza Achcaoucaou lallouchen

Becaria del Departament d'Economia i Organització

d'Empreses de la Universitat de Barcelona

farizaa@ub.edu

|Fecha presentación: 16/11/2011 | Aceptación: 14/12/2012 |Publicación: 21/06/2013

\begin{abstract}
Resumen
El objetivo de este artículo es presentar el protocolo de implantación de diversas herramientas didácticas, así como el nivel de satisfacción de los estudiantes que las utilizan. Los resultados muestran, primero, que no es posible crear un único protocolo aplicable a todos los recursos, debido a las diferencias en los objetivos didácticos existentes. Segundo, la valoración que los estudiantes hacen de la utilización de los recursos es muy positiva, aunque existen algunas diferencias entre las distintas herramientas. Estos resultados permiten mejorar los recursos y adecuarlos al perfil de los estudiantes para que éstos puedan sacar el mayor provecho posible.
\end{abstract}

Palabras clave: WebQuest, ejercicio tutorizado, protocolo, aprendizaje autónomo

\begin{abstract}
Resum
L'objectiu d'aquest article és presentar el protocol d'implantació de diverses eines didàctiques, així com el nivell de satisfacció dels estudiants que les utilitzen. Els resultats mostren, primer, que no és possible crear un únic protocol aplicable a tots els recursos, ateses les diferències en els objectius didàctics existents. Segon, la valoració que els estudiants fan de la utilització dels recursos és molt positiva, tot i que existeixen algunes diferències entre les diferents eines. Aquests resultats permeten millorar els recursos i adequar-los al perfil dels estudiants per què aquests puguin treure’n el major profit possible.
\end{abstract}

Paraules clau: WebQuest, exercici tutoritzat, protocol, aprenentatge autònom

\begin{abstract}
The aim of this paper is to present the implementation protocol of different teaching tools, as well as the students' satisfaction level in their use. The results show, first, that it is not possible to create a single protocol fitting all the resources, because of differences in the teaching objectives. Second, the students' rating of the resources utilization is very positive, although some differences between the analysed resources exist. These results allow improving the resources and bringing them to the profile of the students to make the best use possible.
\end{abstract}

Key words: WebQuest, tutorised exercise, protocol, autonomous learning 


\section{Introducción}

El Espacio Europeo de Educación Superior (EEES) ha supuesto para las universidades el reto de adaptar sus enseñanzas y diferentes asignaturas al nuevo entorno. El proceso de adaptación ha requerido, algunas veces, la creación de recursos didácticos digitales para facilitar y complementar el material docente.

No obstante, una vez diseñadas las herramientas didácticas, es necesario aplicarlas adecuadamente, para ayudar a los estudiantes a adquirir las competencias que se pretende alcanzar con cada tipo de recurso. Además, es necesario plantearse su utilidad para el desarrollo curricular de los estudiantes que las utilizan.

El objetivo de este artículo es doble. En primer lugar, se presenta el protocolo diseñado para la aplicación de herramientas didácticas en formato digital. Por otra parte, se analiza la satisfacción de los estudiantes en el uso de este tipo de recursos para la adquisición de competencias genéricas y habilidades sobre la base de las directrices de optimización de las estructuras educativas de Europa II (Tuning Educational Structures in Europe II 2005).

El uso de herramientas de aprendizaje basadas en las Tecnologías de Información y Comunicación (TIC) debe permitir acercarnos a este nuevo paradigma dominante (Parker 1997, Torre 2009), constituyendo un camino para el desarrollo del aprendizaje autodirigido, uno de los métodos de aprendizaje más necesarios hoy en día, aunque uno de los menos desarrollados dentro de los sistemas tradicionales de enseñanza (Maldonado et al. 1995). Es fundamental emplear enfoques imaginativos para crear nuevos modelos de enseñanza basados en las TIC. Además, la introducción de recursos didácticos basados en las TIC en el proceso de enseñanza-aprendizaje debe contribuir a la construcción del conocimiento (Cronje 1995, Martínez et al. 2011).

Adicionalmente, el actual entorno en el cual se mueve la sociedad está forzando a las universidades a rediseñar los esquemas educativos, con el fin de adaptarse a la realidad social y profesional. Se exigen nuevas metodologías formativas apoyadas en instrumentos más flexibles, dinámicos, y actualizados (Hannan y Silver 2005, Torre 2009).

Sin embargo, las TIC en sí mismas no representan una mejora en la adquisición y desarrollo de los conocimientos, habilidades y destrezas. Para que su uso pueda llevar a un verdadero cambio en las prácticas docentes y el aprendizaje del alumnado, las cuestiones de fondo del modelo de enseñanza tradicional deben ser afrontadas, y por eso se debe ir más allá de la mera impartición de temas y listas de lecturas utilizando soportes visuales (Gros y Kirschner 2006, Area 2007). Diversos autores identificaron los diferentes requisitos que deben regir el diseño, producción y aplicación del aprendizaje autónomo y los recursos de aprendizaje virtual. Según Honebein (1996), los objetivos a cumplir son, entre otros: (1) proporcionar experiencia en el proceso de construcción del conocimiento y aprecio por las diversas perspectivas; (2) integrar el aprendizaje en contextos realistas y relevantes y en la experiencia social; y (3) fomentar el uso de múltiples modos de representación y la autoconciencia en el proceso de construcción del conocimiento. Para Parker (1997), las principales condiciones del diseño son: (1) trabajar con problemas reales y encontrar soluciones en equipo; (2) diálogo permanente entre los participantes y el instructor; (3) retroalimentación de los estudiantes y discusión de temas variados; y (4) implicación de los facilitadores no sólo en los contenidos del curso, sino también en el desarrollo de los materiales multimedia en que se basan. Finalmente, en cuanto a las características de los recursos, Herrington y Oliver (1997) apuntan a: (1) proporcionar actividades auténticas y acceso a las interpretaciones de expertos y el modelado de procesos: (2) apoyar la construcción colaborativa del conocimiento; y (3) proveer para la evaluación integrada del aprendizaje dentro de las tareas.

En concreto, el aspecto principal del diseño y creación de los recursos didácticos en soporte digital es satisfacer las necesidades de aprendizaje del alumnado (tomando como base, por ejemplo, a Marcelo y Lavie 2000), teniendo en cuenta los recursos disponibles (es decir, las instalaciones existentes en las aulas: ordenadores, licencias de software, proyectores de multimedia, etc.), las limitaciones de las plataformas digitales necesarias para apoyar a los nuevos recursos (páginas web, intranet y plataforma Moodle, etc.), así como la tecnología necesaria para acceder a estas nuevas herramientas, ya que el objetivo es facilitar el acceso y disponibilidad, para garantizar que ningún usuario se queda fuera del sistema a causa de unos requisitos técnicos demasiado sofisticados.

El resultado del proceso llevó a la utilización de dos herramientas de aprendizaje autónomo en entorno virtual: las WebQuests (WQ) y los Ejercicios tutorizados (ET). Los dos recursos están pensados para que se dé un aprendizaje activo, el cual permite que el alumnado alcance mejor comprensión, retenga información durante más tiempo y disfrute más de la materia (Felder et al. 1998; Timmerman y Lingard 2003; Ragueras et al. 2009). Los dos recursos se presentan a continuación.

\subsection{WebQuests}

Las WebQuests son lecciones orientadas a la investigación en las que la mayor parte o toda la información se trabaja a través de una web (Dodge 2010). El recurso, tal como lo diseñaron sus creadores, posee la siguiente estructura: (a) Índice o portada, (b) Introducción, (c) Cuestiones / Tarea, (d) Proceso, (e) Evaluación, (f) Conclusión, (g) Créditos, y (h) Guía didáctica. Ejemplos de WebQuests desarrolladas para este proyecto están disponibles en la página web del grupo (www.ub.edu/gidea).

La enseñanza en el área de Organización de Empresas exige al docente acercar el mundo empresarial a los estudiantes. El estudio tradicional de casos puede extender su impacto a través de la utilización de nuevas herramientas de comunicación al alcance de los estudiantes como Internet y/o diversos dispositivos multimedia (Cannings y Talley 2002). Las WebQuests presentan al alumnado situaciones y hechos reales, con acceso a diversos tipos de información que está guiada y disponible, principalmente en la web, lo que permite el trabajo autónomo previsto por el EEES (Quintana e Higueras 2007). La actividad propuesta obliga a los estudiantes a utilizar y transformar dicha información de modo que, después de completar el análisis, síntesis y evaluación, propongan soluciones creativas. Además, permiten motivarlos para llevar a cabo las tareas, ya que, cuando se les plantea una determinada situación empresarial, deben adoptar el rol del gerente de la compañía y resolver el problema tal y como lo harían en un caso real.

\subsection{Ejercicios tutorizados}

A los estudiantes del sistema universitario actual se les pide ser más responsables de su propia formación y tomar la iniciativa en el proceso de aprendizaje, dando paso a un 
aprendizaje más autónomo y autodirigido. Los estudiantes siguen las tres fases del aprendizaje definidas por Zimmerman (2000): (1) fase de anticipación-activación, (2) fase de elaboración, y (3) fase de reflexión y valoración (una aplicación se puede encontrar en Mauri et al. 2009). En este contexto, las herramientas que ayudan a despertar el interés de los estudiantes en tareas de autoaprendizaje son de gran utilidad. Así, los ejercicios tutorizados son entendidos como sistemas instructivos de autoaprendizaje que muestran al estudiante cómo resolver correctamente una determinada actividad de cierta complejidad (mediante la adopción de un método paso a paso).

De nuevo, ejemplos de ejercicios tutorizados desarrollados para este proyecto están disponibles en la página web del grupo.

\section{Datos y análisis}

Aunque no existe un protocolo común para la implantación de todos los recursos, ya que su naturaleza y objetivos didácticos son diferentes, sí que hay partes del proceso comunes. En este apartado se presentan los protocolos específicos de cada una de las herramientas didácticas en soporte digital desarrolladas.

\subsection{WebQuests}

Las WebQuests se implementaron por primera vez en el curso 2008/2009 como recurso didáctico en la asignatura de Dirección General y Estratégica de la licenciatura de Administración y Dirección de Empresas (ADE) de la Universitat de Barcelona, como una parte importante de la evaluación continuada. Así, para superar la asignatura, además de realizar un examen final, el alumnado debe resolver una serie de casos empresariales a lo largo del curso, que suponen el 30\% de la nota final. El diseño de la WebQuest, que se adapta perfectamente a la metodología del caso, la convierte en una herramienta didáctica totalmente adecuada para dicha asignatura. La Figura 1 recoge el proceso seguido en la implantación de estas WebQuests, separando el trabajo autónomo del alumnado (parte sombreada) del trabajo en el aula.

Después de trabajar en clase los temas relacionados con la WebQuest, el profesor de la asignatura anuncia en el aula la publicación de la misma a través de la intranet de la asignatura (plataforma Moodle), así como la fecha de entrega del informe correspondiente. Como consecuencia del volumen de trabajo que supone la búsqueda de información ligada al trabajo de casos empresariales y considerando la dimensión de los grupos de la asignatura de Dirección General y Estratégica en la Universitat de Barcelona, es una tarea realizada en grupos de 2 a 4 personas. Estos equipos de estudiantes se crean al inicio del curso y se mantienen a lo largo del semestre.

Los alumnos disponen aproximadamente de tres semanas para que, fuera del aula, realicen la búsqueda de información y la elaboración del informe final, resolviendo las cuestiones planteadas. Durante esta fase, el profesor asesora y soluciona las dudas que van surgiendo a medida que los estudiantes avanzan en el trabajo.

Pasado el plazo establecido, cada grupo entrega en clase un informe en formato papel para que el docente lo pueda evaluar. El profesor, además de entregar al alumnado las calificaciones de los trabajos, da también correcciones personalizadas de forma individual, así como indicaciones de los errores más frecuentes para todos los alumnos.

Es necesario mencionar además que al inicio de la implantación de los recursos se publicó también en la intranet una encuesta de satisfacción, pidiendo a los estudiantes no sólo que la contestaran, sino también que comentaran cualquier problema o error que pudiera haber en el diseño de la herramienta. Gracias a sus comentarios, los recursos didácticos, así como el protocolo de implantación, se van mejorando continuamente.

\subsection{Ejercicios tutorizados}

Este tipo de herramienta didáctica ha sido aplicada básicamente en las asignaturas de Dirección de la Producción y Economía de la Empresa (ADE) de la Universitat de Barcelona, por ser materias con un elevado porcentaje de contenidos prácticos donde los ejercicios son de gran ayuda en el aprendizaje por parte del alumnado.

En este caso, los ejercicios están diseñados como herramienta de aprendizaje autónomo, por lo que se ponen a disposición de los estudiantes mediante su publicación en la intranet de las asignaturas correspondientes. Para dar a

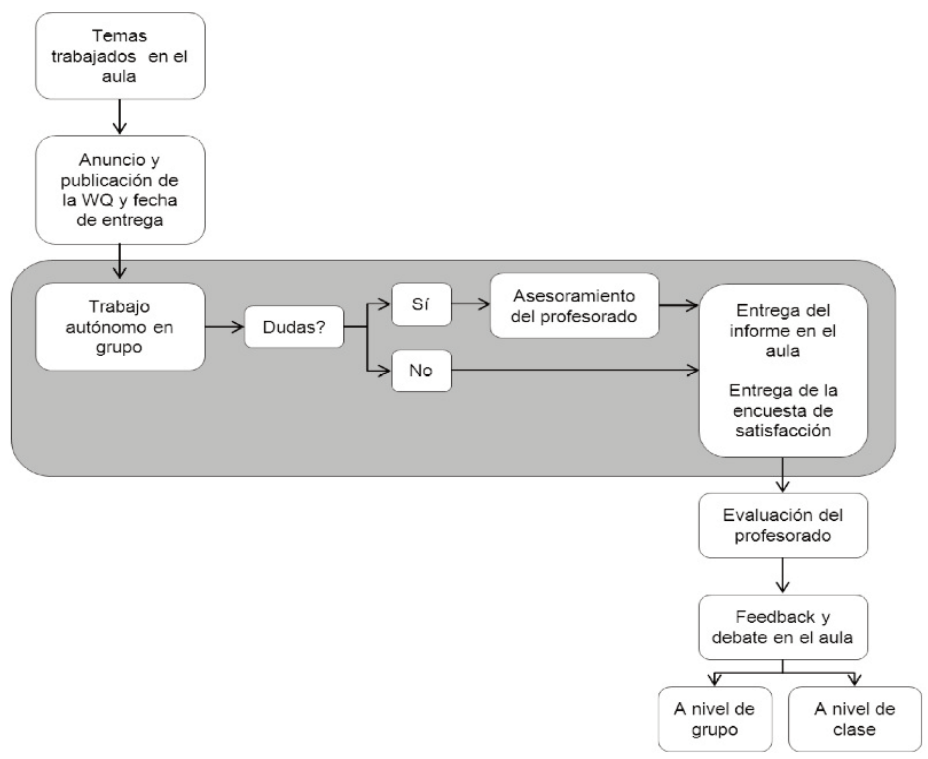


conocer estos recursos a los estudiantes y fomentar su uso, al inicio de curso se proponen un par de actividades como parte de la evaluación continuada evaluable, donde se fuerza la utilización de algunos ejercicios tutorizados, permitiendo al alumnado ver su funcionamiento y tomar conciencia de su utilidad de cara al estudio autónomo.

Como en el caso anterior, el proceso seguido se presenta en la Figura 2. Del mismo modo que para el protocolo anterior, las tareas realizadas por los estudiantes están sombreadas.

El primer paso es publicar el ejercicio tutorizado en el campus virtual (intranet) de la asignatura. A continuación se publica el enunciado del ejercicio de evaluación continuada que se evaluará y que tiene como base el ejercicio tutorizado, que sirve como ejemplo o demostración, indicando la fecha de entrega del ejercicio resuelto.

Una vez entregadas las resoluciones de las actividades, el docente evalúa y devuelve los ejercicios corregidos de forma personalizada a los alumnos, comentando los errores más frecuentes que se dan en estas actividades. El resultado de la actividad se publica en la intranet de la asignatura.

Este protocolo se aplica al primer ejercicio tutorizado propuesto, ya que una vez que los estudiantes están familiarizados con la herramienta su utilización es a cargo del alumnado (autoaprendizaje). Al igual que en el caso anterior se publicó una encuesta de satisfacción con el fin de conocer la opinión de los usuarios del recurso.

\subsection{Análisis de satisfacción}

Para que el diseño e implantación de los recursos didácticos desarrollados tengan éxito, es necesario medir el nivel de satisfacción de los usuarios (Bures et al. 2000; Levy 2007). Para ello, se diseñó un cuestionario en el que los estudiantes valoraron a nivel cuantitativo diferentes aspectos del uso de las herramientas. La escala de valoración utilizada fue la de Likert de 1 a 7 , en la que 1 significaba "totalmente en desacuerdo" y 7 "totalmente de acuerdo". La cumplimentación de la encuesta era voluntaria y anónima entre los estudiantes que habían utilizado los recursos.

El cuestionario consta de tres secciones principales:

"Identificación de datos". El propósito es identificar el recurso que se ha utilizado e incluye una serie de caracterís- ticas que definen el perfil de los estudiantes.

"Evaluación de los recursos didácticos utilizados". Los datos de la segunda sección miden el nivel de satisfacción de los estudiantes con el recurso didáctico.

"Evaluación de competencias y habilidades y el grado de conocimiento adquirido". A los estudiantes se les pide que indiquen, desde una perspectiva global, el grado en que piensan que el uso del recurso didáctico les ha ayudado a mejorar y/o adquirir una serie de competencias generales. Por limitaciones de espacio, esta última parte no se presenta en este trabajo.

\subsection{Descripción de la muestra}

En este estudio se han recogido un total de 523 cuestionarios válidos. Se presentan los resultados de la satisfacción de los estudiantes que han utilizado WebQuests y ejercicios tutorizados, tanto en los grupos de mañana como en los de tarde, en la licenciatura de ADE de la Universitat de Barcelona. La muestra está compuesta por un $60 \%$ de mujeres y un $40 \%$ de hombres con una edad media de 22 años. El 46\% de los estudiantes trabaja, mientras que el 54\% estudia a tiempo completo.

\subsection{Análisis descriptivo}

Con las valoraciones obtenidas del alumnado se ha llevado a cabo un análisis descriptivo que se presenta a continuación. La comparación de los resultados se ha realizado tanto para el recurso en general como diferenciando según el perfil de los alumnos, lo que permite profundizar más en las valoraciones y las diferencias entre los recursos analizados.

La comparación entre la valoración media de cada recurso (Figura 3), muestra cómo los estudiantes valoraron más positivamente los ejercicios tutorizados que las WebQuests, para todos los aspectos analizados.

Este hecho puede responder a los diferentes objetivos didácticos de las dos herramientas, ya que en los ejercicios tutorizados el alumno recibe la resolución de un ejercicio complejo paso a paso (se facilita su aprendizaje y como receptor de información es más pasivo), mientras que en la WebQuest, el alumnado debe buscar información, leer, analizar y solucionar una situación empresarial propuesta

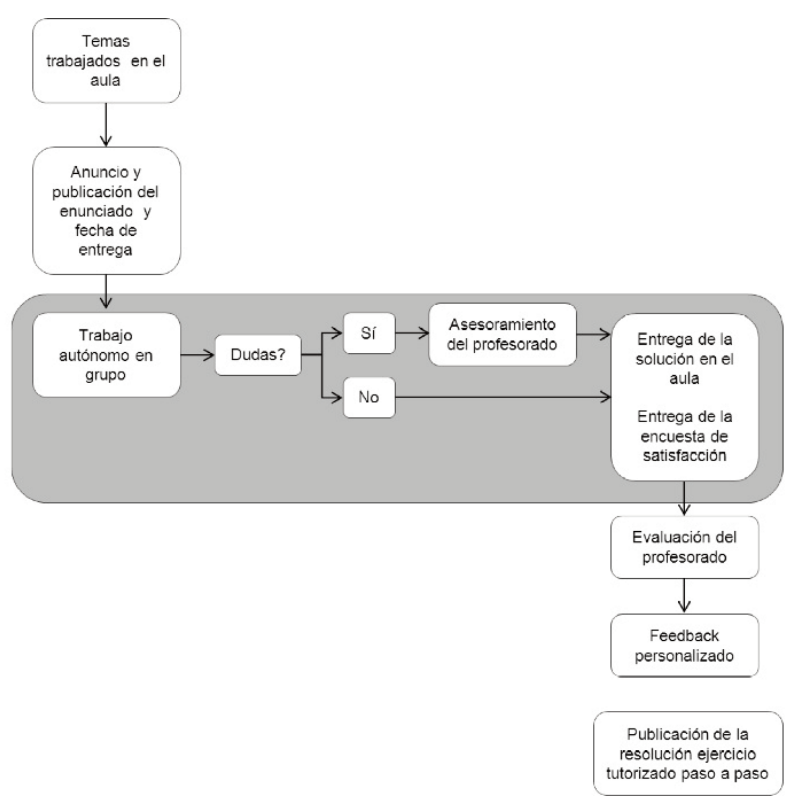




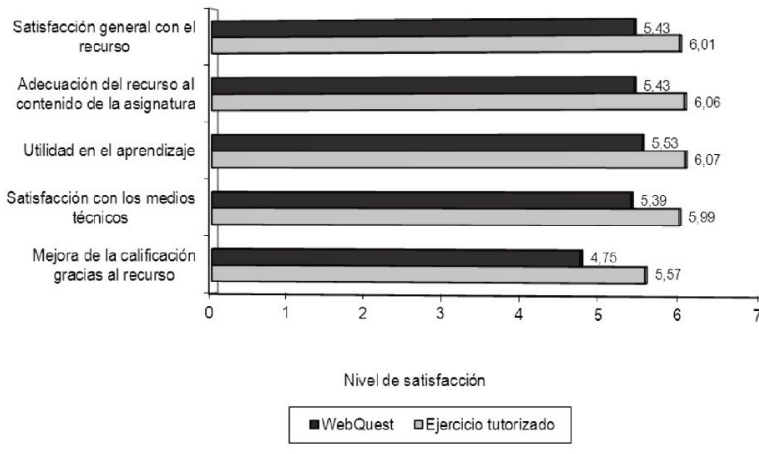

Figura 3. Valoración media de las herramientas analizadas. Fuente: Elaboración propia.

(el aprendizaje le supone un mayor esfuerzo y tiempo de dedicación, ya que se le exige que sea más activo).

El alumnado ha valorado la satisfacción general de las WebQuests con un 5,43 sobre 7. Las valoraciones más positivas son en cuanto a la utilidad en el aprendizaje y la adecuación del recurso al contenido de la asignatura, mientras que el aspecto menos valorado ha sido la mejora en la calificación final de la asignatura (Figura 3).

Respecto a las variables analizadas, son los alumnos que cursan la asignatura por primera vez y a tiempo completo, los que mejor las valoraron, mientras que el alumnado que trabaja y el grupo de repetidores lo hicieron en menor medida (Tabla 1). Cabe destacar que los alumnos repetidores valoraron de forma ligeramente superior que los estudiantes matriculados por primera vez tanto la utilidad en el aprendizaje, como los medios técnicos y la mejora en la nota final de la asignatura.

Una posible explicación, como se ha apuntado antes, es el esfuerzo, tiempo y trabajo que demandan estos recursos a los estudiantes. La disponibilidad de los alumnos que sólo estudian es más elevada que la de los que trabajan, y el conocimiento de la asignatura es inferior para los primeros que para los segundos, de tal manera que la necesidad de asimilar conceptos puede hacer que los estudiantes a tiempo completo de primera matrícula se impliquen más en la realización de las actividades.

De forma global, la valoración media de los ejercicios tutorizados (ET) ha sido superior a la media de las WebQuests (WQ). La satisfacción general con el recurso es de 6,01 sobre 7, por tanto, muy positiva. Las valoraciones medias más elevadas de este recurso coinciden con el anterior, ya que se con- centran en la utilidad en el aprendizaje y la adecuación del recurso al contenido de la asignatura, mientras que el aspecto menos valorado ha sido la mejora en la nota final de la asignatura, también como en el caso antes mencionado (Tabla 1).

De forma comparativa según las variables analizadas, los estudiantes que mejor valoran los ejercicios tutorizados son, globalmente, alumnos que cursan la asignatura por primera vez y que trabajan. En cambio, los alumnos que estudian a tiempo completo y repetidores las valoran menos (Tabla 1). Es remarcable que las diferencias en la valoración media entre los alumnos repetidores y los matriculados por primera vez son muy pequeñas, sólo destaca la diferencia entre la utilidad en el aprendizaje, más valorada por los repetidores, y la mejora en la nota final, más valorada por los alumnos no repetidores.

Se observa que la mayor diferencia respecto a las WebQuest es nuevamente la dedicación y disponibilidad de tiempo de los estudiantes, ya que en este caso los alumnos que compaginan los estudios con el trabajo son los que mejor valoran la herramienta. Esto es porque no requiere un esfuerzo de aprendizaje autónomo muy elevado, o no tanto como en el recurso anterior, sino que en estos ejercicios el alumno puede repasar una metodología de resolución de ejercicios de cierta complejidad que le sirve para reforzar y consolidar los conocimientos ya adquiridos. De forma más genérica, el alumnado es más pasivo que en las WebQuests, ya que recibe información, sin necesidad de realizar búsquedas adicionales.

\section{Conclusiones}

El objetivo de este artículo es doble. En primer lugar, diseñar un protocolo para la implantación de los recursos didácticos (WebQuest y ejercicios tutorizados) diseñados para algunas asignaturas de la licenciatura de ADE de la Universitat de Barcelona, para poner estas herramientas de aprendizaje a disposición del alumnado de la manera más adecuada posible. En segundo lugar, medir la satisfacción del alumnado con estos recursos. Una vez implantadas las herramientas y probado el protocolo en condiciones operativas, las conclusiones extraídas son las siguientes.

Por una parte, los resultados muestran que es posible diseñar un protocolo común, aunque no totalmente igual, para implantar cualquier recurso didáctico. Los principales pasos del mismo son: trabajo de los temas en el aula, anuncio de la actividad y fecha de entrega, trabajo por parte del alumnado con asistencia del profesor si es necesario, entrega de la solución, evaluación del profesorado y feedback.

\begin{tabular}{|l|c|c|c|c|c|c|c|c|}
\hline & \multicolumn{2}{|c|}{$\begin{array}{c}\text { Alumnado } \\
\text { 1a matrícula }\end{array}$} & \multicolumn{2}{c|}{$\begin{array}{c}\text { Alumnado } \\
\text { repetidor }\end{array}$} & \multicolumn{2}{c|}{$\begin{array}{c}\text { Alumnado } \\
\text { tiempo completo }\end{array}$} & \multicolumn{2}{c|}{$\begin{array}{c}\text { Alumnado } \\
\text { que trabaja }\end{array}$} \\
\cline { 2 - 10 } & WQ & ET & WQ & ET & WQ & ET & WQ & ET \\
\hline Satisfacción general con el recurso & 5,47 & 6,05 & 5,00 & 6,03 & 5,51 & 6,01 & 5,41 & 6,07 \\
\hline $\begin{array}{l}\text { Adecuación del recurso al contenido } \\
\text { de la asignatura }\end{array}$ & 5,46 & 6,10 & 5,20 & 6,09 & 5,48 & 6,05 & 5,48 & 6,10 \\
\hline Utilidad en el aprendizaje & 5,55 & 6,10 & 5,60 & 6,12 & 5,48 & 6,14 & 5,43 & 6,03 \\
\hline Satisfacción con los medios técnicos & 5,38 & 6,05 & 5,40 & 5,97 & 5,45 & 6,05 & 5,29 & 5,99 \\
\hline $\begin{array}{l}\text { Mejora de la calificación obtenida } \\
\text { gracias a la utilización del recurso }\end{array}$ & 4,65 & 5,60 & 5,60 & 5,47 & 4,77 & 5,58 & 4,68 & 5,57 \\
\hline
\end{tabular}

Tabla 1. Valoración media de los recursos según las características del alumnado. Fuente: Elaboración propia. 
Por otro lado, en cuanto al nivel de satisfacción del alumnado, existen diferencias entre la valoración de cada recurso docente. Pese a que los estudiantes que han utilizado los recursos implantados manifiestan un elevado grado de satisfacción general, los ejercicios tutorizados han sido mejor valorados que las WebQuests. Esto, creemos que se debe a su diferente objetivo didáctico, ya que las WebQuest obligan al estudiante a trabajar más para adquirir nuevos conocimientos, mientras que con los ejercicios tutorizados se resuelven ejercicios complejos y, por tanto, facilitan el autoaprendizaje por parte de los estudiantes. Aun así, las características mejor valoradas son las mismas en ambos recursos. La mayor diferencia se encuentra si se analizan las valoraciones según el tipo de alumnado. Los estudiantes que más valoran las WebQuests son los que hacen la asignatura por primera vez (más motivación) y que tienen plena dedicación a los estudios, por lo que disponen de suficiente tiempo para buscar información, trabajar en equipo y preparar el informe razonado. En cambio, los estudiantes que mejor valoran los ejercicios tutorizados cursan la asignatura por primera vez, pero trabajan, por lo que disponen de poco tiempo para estudiar y valoran en gran medida todas aquellas herramientas que les pueden facilitar el autoaprendizaje.

La principal limitación de este estudio es el análisis de dos tipos de recursos en asignaturas específicas de organización de empresas. La futura investigación se basará en ampliar el número y variedad de asignaturas, así como continuar con la aplicación de las tecnologías de la comunicación en la docencia universitaria.

\section{Bibliografía}

Area, Manuel. (2007). Algunos principios para el desarrollo de "buenas prácticas" pedagógicas con las TIC en el aula. Comunicación y Pedagogía, 222, 42-47.

Bures, Eva Mary; Abrami, Philip, C. y Amundsen, Cheryl (2000). Student motivation to learn via computer conferencing, Research in Higher Education, 41, 5, 593-621.

Cannings, Terence. R. y Talley, Sue (2002). Multimedia and online video case studies for preservice teacher preparation. Education and Information Technologies, 7, 4, 359-367.

Cronje, J. (1995). Multimedia-Shaping the future of education. Comunicación presentada en Multimedia Conference of AIC Conferences. Sudáfrica, 30 de agosto. http://hagar.up.ac.za/catts/abc/madnes95.html.

Dodge, Bernie (2010). What is a WebQuest? [en línea] http://webquest.org/ [Consulta: septiembre de 2011]

Felder, Richard M., Felder, Gary N. y Dietz, E. Jacquelin (1998). A longitudinal study of engineering student performance and retention. V. comparisons with tradicionally-taught students. Journal of Engineering Education, 87, 4, 469-480.

Gros, Begoña y Kirschner, Paul (2006). La recerca sobre la docència a la universitat: l'ús d'entorns electrònics en l'educació superior. Quaderns de Docència Universitària, 7. ICE Universitat de Barcelona.

Hannan, Andrew y Silver, Harold (2005). La innovación en la enseñanza superior enseñanza, aprendizaje y culturas institucionales. Madrid: Narcea.

Herrington, Jan y Oliver, Ron (1997). Multimedia, magic and the way students respond to a situated learning environment. Australian Journal of Educational Technology, 13, 2, 127-143.

Honebein, P. (1996). Seven goals for the design of constructivist learning environments. En Brent G. Wilson (Eds.), Constructivist Learning Environments: Case Studies in Instructional Design. Englewood Cliffs: Educational Technology Publications, 11-24

Levy, Yair (2007). Comparing dropouts and persistence in e-learning courses. Computers \& Education, 48, 2, 185-204. http://www.qou.edu/arabic/researchProgram/eLearningResearchs/eLDropout.pdf

DOI: 10.1016/j.compedu.2004.12.004

Maldonado, L., Díaz, W., León, I., Monroy, B. y Rueda, R. (1995). Creación de hipertextos educativos. Nuevas Tecnologías aplicadas a la Educación Superior (Vol. 5.). Bogotá: ICFES y Pontificia Universidad Javeriana. Marcelo, Carlos y Lavié, José Manuel (2000). Formación y Nuevas Tecnologías: Posibilidades y condiciones de la teleformación como espacio de aprendizaje. Bordón, 52, 3, 385-406. http://prometeo.us.es/idea/miembros/o1-carlos-marcelo-garcia/archivos/Formacion\%20y\%20NNTT.pdf

Martínez, Carmen., Cruz, José Luis., Ferrer, Chantal, Martínez, Domingo, Muñoz, Vicente, Roldán, Clodoaldo, Utrillas, Pilar, Coll, César, Martínez, José Antonio, Pedrós, Roberto, Tena, Fernando, Valor, Enric, Pons, Amparo, Barreiro, Juan Carlos, Martínez, Manuel, Garcia, Rosa, Ponsoda, Xavier, Cervera, María Luisa, Capaccioni, Romana, González, Fernando, Sanz, Amparo. (2011). La evaluación y seguimiento del estudiante de forma telemática: El proyecto Cuestionarios. @tic. revista d'innovació educativa, 6, 91-95 http://ojs.uv.es/index.php/attic/article/view/241/394

Mauri, T., Colomina, R., Martínez, C. y Rieradevall, M. (2009). La adquisición de las competencias de autorregulación. Análisis de su concepción y aprendizaje en diferentes estudios universitarios. Revista d'Innovació i Recerca en Educació, 2. 2, 33-60.

Parker, Angie (1997). A Distance Education How-To Manual: Recommendations From the Field. Educational Technology Review, 8, 7-10.

Quintana, Jordi y Higueras, Elisabet (2007). Les Webquests, una metodologia d'aprenentatge cooperatiu, basada en l'accés, el maneig i l'ús d'informació de la Xarxa. Quaderns de Docència Universitària. 11. Barcelona: ICE Universitat de Barcelona.

Ragueras, Luisa M., Verdú, Elena, Muñoz, María F., Pérez., M., de Castro, Juan P. y Verdú, María Jesús (2009). Effects of competitive e-learning Tools on higher education students: a case study. IEEE Transactions on Education, 52, 2, 279-285. http://ieeexplore.ieee.org/stamp/stamp.jsp?arnum ber $=04909477$

Rodríguez, M. Luisa (coord.) (2008). Dels estudis universitaris al món del treball. Barcelona: Publicacions i Edicions UB.

Timmerman, B. y Lingard, R. (2003). Assessment of active learning with upper division computer science students en FIE 33rd Annual Frontiers in Education (FIE'O3), 3, S1D-12.

Torre, Saturnino de la (2009). La Universidad que queremos, estrategias creativas en el aula universitaria. Revista Digital Universitaria, 10, 12, 1-17. 
http://www.revista.unam.mx/vol.10/num12/art89/int89 .htm

Tuning Educational Structures in Europe II (2005). Final Report. Pilot Project - Phase 2.

Zimmerman, B. (2000). Attainment of self-regulation. A social cognitive perspective. En M. Boekaerts, P.R. Pintrich, y M. Zeidner (Eds.), Handbook of self-regulation. San Diego, CA: Academic Press, 13-39. 